\title{
Vivendo em liberdade? Homossexualidade, diferenças e desigualdades entre brasileiros na Espanha
}

\author{
Isadora Lins França*
}

\section{Introdução}

Recentes trabalhos têm indicado a variação de movimentos migratórios de brasileiros para a Espanha e de espanhóis para o Brasil. Tais movimentos se intersectam de modo fundamental às mudanças nas situações econômicas de ambos os países. Se até meados dos anos 2000 havia uma tendência ao incremento de imigrantes brasileiros na Espanha (FERNANDES, NUNAN: 2008), após a crise econômica de 2007, da qual aquele país ainda não se recuperou, essa tendência passa a decrescer progressivamente. Em 2012, quando realizei a maior parte da pesquisa de campo que dá origem a este $\operatorname{artigo}^{1}$, a presença de brasileiros na Espanha era ainda expressiva, mas encontrava-se em pleno decréscimo: dados do Instituto Nacional de Estadística da Espanha (INE-ES) apontavam, por exemplo, que em 2012 a presença de estrangeiros brasileiros na Espanha havia reduzido 10\% em relação ao ano anterior: de cerca de 86 mil, passava-se a 78 mil brasileiros no país, aproximadamente 2 .

Por outro lado, a situação econômica no Brasil no momento em que realizei a pesquisa era de relativa prosperidade, com baixos índices de desemprego, inflação controlada e crescimento regular. Em relatório de 2013, relativo a dados de 2011, registra-se a existência de um fluxo migratório de jovens espanhóis que buscavam trabalhar ou investir no Brasil, movimento coincidente com o agravamento da crise na Espanha ${ }^{3}$. Apesar disso, o relatório afirma que apenas uma minoria dos imigrantes brasileiros entrevistados em Portugal e Espanha desejavam retornar ao Brasil. A maior parte dos entrevistados que pretendia permanecer na Espanha ou se declarava indeciso a esse respeito ou apontava como motivo o "nível de vida superior" que levavam naquele país, bem como a nova inserção laboral (ICMPD, 2013: 24).

\footnotetext{
* Professora do Departamento de Antropologia do Instituto de Filosofia e Ciências Humanas da Universidade Estadual de Campinas (IFCH-UNICAMP) e pesquisadora colaboradora do Núcleo de Estudos de Gênero Pagu/Unicamp
} 
Os números brevemente mobilizados indicam uma variedade de tendências e apresentam um panorama mais geral dos fluxos migratórios entre Brasil e Espanha, mas não esgotam os aspectos que giram em torno das articulações entre mobilidades, diferenças e desigualdades. Quando lidamos com questões relacionadas à sexualidade, particularmente, as estatísticas apontam ainda menos caminhos para a análise, já que se trata de variável pouco investigada no geral. É preciso considerar que as posições de sujeito habitadas por imigrantes nos trânsitos que efetuam por entre fronteiras nacionais evidenciam também diferentes desejos, esperanças e aspirações. Além disso, se constituem num complexo jogo de intersecção de diferenças como gênero, sexualidade, classe social, cor/raça, etnicidade, entre outros. Interrogar tais processos pressupõe necessariamente o exame da produção de diferenças em e através umas das outras, ou seja, o modo como sexualidade se produz a partir de raça, como raça se produz a partir de gênero, como gênero se produz a partir de classe e assim por diante e em revés (Mc CLINTOCK, 2010).

Neste trabalho, procuro abordar as posições sociais ocupadas por imigrantes brasileiros que se autoidentificaram como gays durante etnografia que realizei no ano de 2012 na cidade de Barcelona, tendo como foco a circulação de pessoas, informações e bens num contexto global de mercado relacionado à homossexualidade. Ainda, o faço a partir do contraste com a experiência de turistas gays na cidade e no contexto de promoção de uma narrativa da cidade que a associa a um vibrante e bem-sucedido mercado voltado para gays e lésbicas. Meu argumento é o de que os deslocamentos realizados pelos interlocutores permitem interpelar os significados associados à cidade de Barcelona como lugar de "liberdade" e de fruição. Quando contrastamos o discurso tão comum ao mercado de turismo com o cotidiano dos trabalhadores imigrantes que são fundamentais para a manutenção desse setor, percebemos também diferentes tipos de constrangimentos sociais enfrentados pelos imigrantes na busca pelo seu sustento diário - e as possibilidades de agência diante desses mesmos constrangimentos.

Aposto fortemente que contextos relacionados ao mercado também se prestam à produção de diferenças e desigualdades, não estando dissociada do Estado ou dos movimentos sociais ${ }^{4}$. Utilizo, aqui, o mercado de lazer voltado para gays e lésbicas em Barcelona como contexto e cenário para a reflexão sobre mobilidades e trânsitos de homens gays brasileiros. Busco olhar para consumo, trabalho e mobilidade de modo articulado, investigando como os deslocamentos realizados pelos sujeitos em meio a esse cenário afirmam, desafiam e deslocam normas e regulações. Tenho em conta, ainda, o problema de como as diferenças e desigualdades sociais que marcam o contexto brasileiro se reeditam e se deslocam em espaços transnacionais a partir dos trânsitos realizados pelos próprios sujeitos - ao mesmo tempo em que se produzem marcadas por convenções relacionadas a gênero, sexualidade, raça e nacionalidade. 


\section{Vivendo em liberdade? Circuitos e circulações}

Um intenso trânsito de informações, objetos e pessoas estabelece uma espécie de circuito global de consumo associado à homossexualidade. Uma expressão desse mercado gay de caráter global se dá a partir de uma determinada cena cultural que reúne homens musculosos, consumo de psicoativos sintéticos e música eletrônica, cuja expressão eu já havia observado, em âmbito local, na cidade de São Paulo (França, 2012). Barcelona é uma das cidades centrais desse circuito, sendo considerada um dos destinos turísticos globais mais fortes entre o público gay, o que também é intensificado pela sua localização mediterrânea e pela sociabilidade fortemente marcada pela praia e exposição do corpo, bem como por uma ideia largamente difundida de que seria uma cidade em que há mais liberdade em relação à homossexualidade - como me foi enfatizado por meus interlocutores de São Paulo e pelos brasileiros que encontrei na pesquisa de campo na Catalunha. Ali também acontece o Circuit, o maior festival europeu de música eletrônica voltado para gays, que acompanhei durante a pesquisa e que menciono mais adiante, destacando a presença de brasileiros, turistas e imigrante, no evento.

Durante o período de realização da pesquisa, um vetor do deslocamento de brasileiros que poderíamos identificar provisoriamente como $\mathrm{LGBT}^{5}$ estava relacionado ao envolvimento no ativismo, na produção artística e na universidade, campos para os quais a agitada cena política e cultural de Barcelona oferece uma oportunidade de troca e de atuação. A indústria de construção civil e o trabalho com cuidado, serviços domésticos e turismo também figuravam como possibilidade de ocupação para brasileiros que desejavam viver na Espanha, independente de sua sexualidade. Durante a pesquisa de campo no contexto dos lugares de lazer relacionados à homossexualidade na cidade encontrei rapazes brasileiros que realizavam uma ou várias dessas ocupações, revezando-se entre as diferentes saídas possíveis na batalha cotidiana de ganhar a vida no país.

Ainda, a Espanha de modo geral parece ser um país central para imigrantes brasileiros gays ou, pelo menos, para os que se engajam no mercado do sexo nesse projeto migratório. Algumas ONGs espanholas dão conta de que a maioria dos chaperos $^{6}$ em Madri ou Barcelona são brasileiros ${ }^{7}$. Em São Paulo, durante minha pesquisa de doutorado (França, 2012) era recorrente a fala, em tom jocoso, de que alguns rapazes diziam viajar à Espanha a turismo ou para viver, quando na verdade tinham como objetivo o trabalho como chaperos, ocupação bastante desvalorizada, ainda que bastante presente no cotidiano dos espaços de sociabilidade voltados para gays no Brasil, como em outros países. Assim, se, por um lado, a relação entre a migração de homens brasileiros e a atuação como chaperos na Espanha está longe de ser predominante no que concerne aos trânsitos mais gerais de brasileiros (gays ou não) em direção àquele país, por outro lado, no contexto do mercado de lazer voltado para gays e lésbicas 
em grandes cidades da Espanha frequentemente se associa o trabalho sexual a imigrantes, dentre os quais brasileiros representariam uma importante parcela. Tal associação era motivo de incômodo para alguns dos meus interlocutores de pesquisa, que se ofendiam com propostas em bares ou boates. Para outros, que efetivamente trabalhavam como chaperos, tratava-se de tirar vantagens de outras convenções que associariam ainda os brasileiros a estereótipos relacionados ao vigor e à disposição sexual. Como pesquisadora, me pareceu importante tematizar aspectos envolvendo o sexo em troca de bens, dinheiro ou mesmo de oportunidades de acesso a lugares e serviços na análise das possibilidades de agência e deslocamento vividas por imigrantes brasileiros gays em Barcelona.

Passo, então, a articular as questões que expus de forma um pouco introdutória no início deste artigo com notas etnográficas oriundas da pesquisa de pós-doutorado. No período em que realizei minha pesquisa de campo em Barcelona, o website de turismo e agenda cultural da prefeitura mantinha uma sessão que tratava de diversidade sexual, disparando o slogan: "Barcelona, uma capital que inspira a viver em liberdade". Essa sessão demarcava um sinal distintivo da cidade de Barcelona: a valorização da diversidade e da liberdade sexual, descrevendo a cidade como aberta, plural, tolerante, o que se atestava pela presença de um mercado gay vibrante e moderno. Na mídia brasileira voltada ao público gay, também é comum encontrar matérias que descrevem a cidade de modo idílico, como uma reportagem de 2009, que caracteriza Barcelona como "gay até a medula", dona de um ar "descolado" e "descompromissado", marcada pela festa, informalidade, flerte e pela presença de homens desejáveis e disponíveis, "malhados e dourados".

O Festival Circuit, que observei em Barcelona é um dos cenários importantes deste trabalho, também faz parte desse contexto. Trata-se de conjunto de festas ininterruptas que acontece durante 10 dias e que procura abarcar um amplo público gay masculino entre os seus 70 mil participantes, mas que tem na imagem do seu consumidor ideal um homem gay, branco, musculoso, jovem e apto a certo estilo de consumo. As festas de música eletrônica, para milhares de pessoas, em locações diversas pela cidade, são de responsabilidade do grupo empresarial Matinée, de Barcelona, que convida outros grupos empresariais do universo do mercado gay de Amsterdam, Madrid, Tel Aviv, Londres e também do Brasil, que participa do festival com a festa organizada pela boate paulistana The Week, onde realizei pesquisa etnográfica para meu doutorado.

O recurso ao turismo e ao "cosmopolitismo" é bastante explorado pelo festival que, de fato, recebe um contingente notável de estrangeiros, cerca de $70 \%$ do público. Destes, $40 \%$ vêm de países europeus (franceses, ingleses, italianos, alemães, suecos, holandeses e belgas, principalmente) e $30 \%$ vem de outras partes do mundo, com o Brasil liderando o número de participantes nãoeuropeus (cerca de 4 mil pessoas), seguido de Estados Unidos, Austrália, Israel, Rússia e Canadá. Todos os brasileiros que conheci que tinham ido ao festival na 
qualidade de turistas, desde o Brasil, eram profissionais liberais, em torno dos seus 35 anos, residentes em São Paulo, e haviam contratado pacotes turísticos especialmente para o festival.

Argumento aqui que iniciativas como a do Festival Circuit concorrem para a produção de oposições entre a Europa, lugar da diversidade sexual e da fruição da liberdade num mundo cosmopolita tão "moderno" como "global", e mundos menos "livres", "menos globais" e "menos modernos". Um trecho de reportagem do jornal El Periódico, de 2012, descreve uma festa do Circuit e sublinha: "no caminho para a festa, se fala mais línguas do que na sede da ONU, gays e lésbicas (elas não passam de centenas) de todo o mundo, entre árabes, estadounidenses, israelenses, brasileiros, russos, italianos, gregos, porém, se entendem com apenas alguns gestos" ${ }^{\prime \prime}$. Se a sede da ONU aqui é construída como uma figura de metonímia do mundo todo, o festival global se apresenta como uma espécie de mundo gay em miniatura, cuja diversidade se expressa nas línguas faladas e nos países de procedência, que indicam certa diferença cultural, até que uma identidade gay universal estabeleça, com base em alguns gestos, a consonância.

Essa perspectiva também aparece nos releases do festival, destacando sua "função social":

O Circuit Festival desempenha importantíssimo papel social entre a comunidade gay e lésbica, pois oferece ambiente seguro e relaxado em que eles podem se reunir ano após ano. Não por acaso, para alguns participantes, ser visíveis como homossexuais, encontrar parceiros ou simplesmente relacionar-se livremente em seus países de origem é difícil ou praticamente impossível, por isso esperam o festival durante o ano todo para se expressar sem medos, ampliar seus círculos e se encontrar com conhecidos do mundo todo. O festival tem contado com alcance mundial, graças ao público crescente que vem do Brasil, Estados Unidos, Egito, Líbano, Rússia, Austrália e até mesmo Tailandia ou China (Matinée GROUP, 2013)"9.

Eventualmente, o Brasil aparece no rol de países cuja presença no festival é importante e nos quais a homossexualidade se cerca de intolerância. No jornal catalão La Vanguardia, em matéria de 2013, a organização do festival afirma que "o crescimento de participantes de países como Brasil, Egito ou Rússia se deve ao contexto econômico desses países, mas também à falta de liberdade ou tolerância com respeito à sua orientação sexual, sendo que os que podem passar uns dias em Barcelona, o fazem de modo a poder desfrutar plenamente do seu tempo livre" [tradução livre ${ }^{10}$. Assim, nesses países, a conjunção entre um bom momento econômico e a falta de liberdade e tolerância em relação à sexualidade teria sido responsável por uma espécie de fuga - controlada, ou seja, apenas por alguns dias, para turismo e não para permanência ou trabalho 
- para Barcelona. Observe-se, além disso, que a ideia da cidade como refúgio adequado para "LGBT" - embora com destino e atividades definidos e data certa para voltar - aplica-se aqui, embora não evoque a figura jurídica do refúgio. Cabe notar também que essa produção do "outro" não é apenas espacial, mas também temporal, como bem destaca Doreen Massey (2012), reeditando-se antigas convenções que associam territórios à adesão a determinados sistemas de valores tradicionais ou modernos.

Tal discurso, porém, não se restringe apenas à mídia e à versão oficial do festival, o que nos impele a levar a sério o modo como alguns desses enunciados ganham sentidos e ressonâncias particulares no modo como brasileiros imigrantes constroem narrativas da sua estadia na cidade. Lucas, por exemplo, empregado de uma loja de cuecas e sungas para gays no bairro do Eixample ${ }^{11}$, carioca, branco, musculoso e nos seus 30 anos me explicou:

aqui tem muita liberdade, $70 \%$ das pessoas são liberais $e$ você anda de mão dada numa boa no meio da rua. Você vai ver o tanto de homem gay nessa calçada [estávamos no centro gay do bairro do Eixample], ainda mais na época do Circuit, todos com shortinho e camiseta totalmente cavada. Faz uns meses que fui pro Rio e fui andar com um shortinho assim perto da praia, quando eu e meus amigos percebemos que todo mundo olhava feio ou espantado pra gente. Virei pra ele e disse: "viado, tá todo mundo olhando pra gente!". Daí a gente vê a diferença entre Brasil $e$ Espanha. (entrevista com Lucas, Barcelona, julho de 2012).

A fala de Lucas se assemelha a outras situações em que presenciei a articulação, por parte dos meus interlocutores imigrantes, de versões próprias da liberdade associadas ao contexto europeu catalão. Narrativas como a sua, contudo, nos colocam de certa maneira o desafio de abordar criticamente uma construção positivada de certa versão da homossexualidade que privilegia expressões mais visíveis do mercado e tem na tolerância uma espécie de índice civilizacional. Atentar para o contexto de circulação das pessoas e para diferentes posições de sujeito permite perceber como a liberdade enunciada em muitos momentos é vivida e negociada a partir de constrangimentos sociais que expõem desigualdades diante dos regimes de mobilidade (SCHILLER, SALAZAR, 2012) pelos quais circulam imigrantes e turistas no mercado de lazer e do sexo da cidade.

Pablo, que não é brasileiro, mas um venezuelano de 50 anos, me apresentou parte dos meus interlocutores brasileiros e que conheci no bar de um "hotel heterofriendly"12 no Eixample. Pablo é engenheiro e reside em Barcelona há cerca de 10 anos. Quando perguntei-Ihe sobre o Festival Circuit, esperava uma resposta entusiasmada, espantando-me frente à sua reação de profundo desgosto: "no, por favor, ya me había olvidado de Circuit, ah, no!". Diante da minha surpresa 
e das explicações de Pablo, fui entendendo que, se para a profusão de turistas esse é um grande evento, para Pablo significa trabalho duro em condições ainda mais adversas que o trabalho que o engenheiro realiza como garçom em uma grande sauna gay.

Apesar de não se sentir realizado profissionalmente, Pablo não tem intenção de procurar outro trabalho, considerando-se até feliz por ter sido promovido da área da limpeza para o balcão da sauna. Queixa-se de que, na época do festival, o movimento aumenta muito e o trabalho se torna insuportável. Segundo ele, a sauna se enche de homens que aparecem bastante alterados em razão do uso de psicoativos e os funcionários têm de agir para separar brigas e socorrer clientes que passam mal.

Pablo conheceu Barcelona a turismo e narra ter decidido permanecer por causa da liberdade vivida nas pegações ${ }^{13}$ da montanha de Montjuic, um dos cartões postais da cidade - e que, numa versão sexualizada, é conhecida pelos gays como um clássico lugar de pegação. Ainda que se ressinta do trabalho, da solidão e da inadaptação a um universo de consumo gay em que se vê como um sujeito pouco desejável - Pablo é mais velho, muito magro, baixo e latino -, o venezuelano não cogita voltar para seu país de origem, que considera muito fechado à homossexualidade e destruído pelo chavismo. Quando o conheci, estava acompanhado de um soldado americano que descansava de temporada no Afeganistão no terraço do hotel hetero friendly da cidade, no bairro de Eixample.

Em um quiosque voltado para gays da praia de Marbella, Pablo me apresentou Jonas, um rapaz mineiro de cerca de 30 anos, bronzeado de sol, sempre sorridente. É seu colega na sauna, trabalhando na área da limpeza, vivendo há 6 anos com documentos de permanência ainda pendentes. Detesta o trabalho que faz no que é, segundo ele, a pior ocupação possível ali: tem de limpar tudo, merda, esperma, preservativo, e vai muita gente só para se colocar ${ }^{14}$. O trabalho da limpeza de espaços para sexo talvez possa ser considerado aqui também como uma espécie de "trabalho sexual", borrando fronteiras entre territorialidades, lugares, sujeitos, práticas, corpos e fluidos e operando a partir de noções de puro/impuro que organizariam também escalas morais. Produzirse-ia aqui uma analogia, no âmbito do trabalho, com o borramento de fronteiras que também verificamos entre mercado do lazer e mercado do sexo em muitos outros aspectos em que se observa a circulação de pessoas, dinheiro e categorias nesse contexto de mercado voltado para a homossexualidade na cidade ${ }^{15}$.

De todo modo, Pablo e Jonas compensavam simbolicamente o fato de ocupar posição tida como desvalorizada no espaço da sauna ao comentarem jocosamente sobre como os clientes podiam cair no ridículo quando procuravam ocultar dos funcionários o fato de que estavam colocados pelo uso de psicoativos ilícitos, denunciando-se pelos tiques e movimento incessante das mãos e dos pés. Ambos também reclamavam dos clientes e gerentes que tratavam os funcionários com pouca polidez. A conversa dos dois girava em torno das fofocas 
sobre o ambiente de trabalho: o colega cubano havia falado mal de Jonas e este alegava que os cubanos não trabalhavam nada. Além do cubano, citou também um chinês, outro brasileiro e um colombiano. O único espanhol que trabalhava nesse espaço foi descrito como retardado e lento.

Diante da crise na Espanha, Jonas pensava em emigrar para o Canadá e juntar algum dinheiro ou voltar para o Brasil. Apesar disso, falava todo o tempo da insegurança das grandes cidades brasileiras e fazia cálculos sem parar sobre a equivalência em termos de acesso ao consumo no Brasil e na Espanha ${ }^{16}$. A contabilidade era bastante detalhada e invocava o custo de vida e o acesso ao lazer nos ambientes gays e a roupas de grife. O que esse custo deixava de transparecer, ainda, eram as oportunidades de consumo e acesso que Jonas obtinha apenas se aproximando das pessoas com alguma malícia, simpatia e aparente ingenuidade - além de, eventualmente, fazer uso da sua aparência, já que era um rapaz bonito. Na Espanha ou no Brasil, Jonas aproveitava-se da situação de deslocamento e das possibilidades de explorar a diferença em termos de nacionalidade a fim de obter acesso a bens, serviços e ambientes dos quais de outra maneira não poderia desfrutar. Isso tudo estava também relacionado a trocas sexuais ou mesmo a uma simples situação de flerte. Quando perguntei a Jonas porque morava em Barcelona, me explicou:

no Brasil eu sou só mais um. Aqui não, sou brasileiro, já querem conversar, já chama a atenção, pois brasileiro faz sucesso. E agora quando fui para o Brasil, já tenho um sotaque diferente, então se me perguntam, digo que sou espanhol e daí a pessoa já se interessa porque não tem como saber, né? Digo que sou espanhol e falo português. Às vezes digo que sou meio espanhol, meio italiano, já é sucesso em dobro, né? Daí, já imagina... Fui a São Paulo faz uns meses, quando fui pra visitar minha irmã, e conheci na Paulista um cara, que me levou para jantar, depois para a casa dele, passei super bem, lá, em Higienópolis. (entrevista com Jonas, Barcelona, janeiro de 2013).

Assim, Jonas agia a partir da sua posição de sujeito e da possibilidade de manejá-la que a experiência de deslocamento internacional lhe proporcionava, "atuando a brasilidade" (PISCITELLI, 2013) e agenciando de certo modo o que no âmbito profissional o relegava a trabalhos com pouca segurança. Suas possibilidades são parecidas com as de Juninho que, entre os meios de que dispunha para ganhar algum dinheiro ou para apenas participar de um universo de consumo e lazer a ele vedado, elencava também o sexo com outros homens, especialmente turistas. Juninho havia emigrado de Feira de Santana para Barcelona, com 17 anos, seguindo sua mãe, que se casara com um espanhol, o que ele também pretendia fazer em breve. Já havia cerca de 7 anos que residia na Espanha e seu objetivo mais urgente, quando o conheci, era conseguir um 
trabalho no Mc Donald's como atendente, esperando que isso o possibilitasse a entrada no mundo dos empregos formais na Espanha.

Embora Juninho descrevesse o balneário de Sitges, ao lado de Barcelona, como um "paraíso gay", fez questão de ressaltar em entrevista o quanto esse paraíso se opunha ao cenário que encontrou logo que chegou na Espanha, tendo ido morar na cidade de Sória. Num misto de espanhol e português, conta que em Sória não há viado, tem que ser discreta, porque eles não aceitam. Eles não vão por aí perdendo plumas, quando vão a Madri que as plumas caem ${ }^{17}$. Enquanto a oportunidade na lanchonete multinacional não vinha, seu leque de trabalhos era amplo:

trabalho de marinete, de empregada doméstica, limpo apartamento, dou banho no cachorro, penteio. Trabalhei em fábrica, de camareiro, ajudante de cozinha, também vendo salgado e doces pro pessoal das lojas aqui perto. Trabalhei de carpinteria. Já fiquei com outros caras que não são meu marido, mas pelo dinheiro. 200 euros, 300 euros, me pagavam, conheço todos os hotéis de luxo de Sitges. Tinha cada cliente bom, passei a noite com dois franceses uma vez, com moet $x$ chandon, morango com chocolate, hotel 5 estrelas, passei cada noite tão bem que você não acredita. (entrevista com Juninho, Barcelona, julho de 2012).

Tendo um irmão encarcerado na Espanha por tráfico de drogas, Juninho finaliza sua fala dizendo que a Espanha é boa, pero hay que andar na linha. A experiência do encarceramento não está distante da vida de imigrantes brasileiros na Espanha, seja em decorrência do envolvimento com atividades consideradas ilegais desempenhadas pelos imigrantes - que muitas vezes têm de recorrer ao mercado informal de trabalho ou a essas atividades na ausência de documentos que os permitam adentrar o mercado formal - da própria situação irregular como imigrantes, ou de acusações que articulam as duas posições, como menciono adiante no caso de $\operatorname{Marcos}^{18}$.

As histórias de Juninho e Jonas são exemplares no sentido de revelar possíveis agenciamentos de gays brasileiros imigrantes, que vivem na Espanha exercendo ocupações variadas de forma instável e com baixas remunerações. Isso imprime um caráter bastante imprevisível ao seu cotidiano e demanda habilidade no sentido de criar e aproveitar oportunidades de sobrevivência que se situam nas fronteiras entre o legal e o ilegal, o formal e o informal, procurando jeitos de se virar e de se garantir enquanto circulam pela cidade ${ }^{19}$.

As histórias também revelam o papel intermitente e flexível que o sexo transacional pode ter na vida desses rapazes, sendo que a fixação como trabalhador do sexo era só uma dessas possibilidades. Fazer programas era um caminho cogitado em algum momento por parcela dos meus interlocutores, seja 
porque recebiam propostas de outros homens em locais de sociabilidade, numa associação direta entre brasileiro e trabalhador do sexo, ou porque essa ocupação se apresentava como um recurso entre outros num momento de dificuldade. Não obtive narrativas em que essa atividade aparecia particularmente como um problema, apresentando-se como mais uma possibilidade de luta pela sobrevivência num contexto adverso.

Finalizo este trabalho trazendo a história de Marcos, de cerca de 30 anos, moreno, recifense. Marcos já trabalhava como michê no Brasil, vindo a exercer a mesma ocupação na Espanha, além do trabalho como gogo boy ${ }^{20} \mathrm{em}$ festas e clubes, bem como numa ONG de prevenção às DST/Aids. Como agente de prevenção, conseguia acesso às caras festas Circuit, onde aproveitava para se divertir e para estabelecer relações com possíveis clientes futuros. Estava sempre em trânsito entre países como Áustria, Bélgica, Alemanha, Holanda, Suíça e Dinamarca, de modo a se mostrar como novidade no mercado do sexo em cada contexto. Dizia que ainda era possível viver como trabalhador do sexo na Espanha, mesmo com a crise, desde que se estivesse em movimento constante por outros países europeus.

Mesmo tendo sido abandonado durante a infância e adolescência no Brasil, o momento de maior sofrimento na sua narrativa surge quando descreve as prisões em decorrência do seu estatuto de imigrante ilegal combinado a acusações de facilitação da prostituição. As frases falam de sentir-se só, deprimido, fragilizado, vulnerável, de passar por uma experiência horrivel, de sentir-se um lixo. A esses sentimentos, Marcos atribui a escolha de casar com um espanhol mais velho, que the possibilitou a legalização de sua situação:

Foi o primeiro [marido], o que me entreguei de corpo e alma. Ele chegou justo no momento em que eu estava mais fragilizado. Me sentia só, me sentia deprimido, fazia pouco tempo que eu tinha saído da prisão. Fui preso por conta do tema da prostituição. Não é proibido se prostituir, mas ganhar dinheiro em cima da prostituição e eu estava no piso de um amigo que estava sendo investigado e quando a polícia chegou eu estava ali dentro, sem documentos, não estava legal no país. E me levaram não só por estar ali dentro, mas por estar ilegal no país. Você vai preso, eles podem te manter preso por 48 horas, eles liberam com uma carta de expulsão, que você pode tentar recorrer e trocar por uma multa, e se não é feito esse procedimento, você é mandado para um centro de detenção de imigrantes e nesse centro você pode estar 40 dias preso e depois deportado. Fiquei dois dias. Foi uma experiência horrível, me senti um lixo, me senti como um lixo. Imagina você não ter feito nenhum crime e estar sendo tratado como um criminal (entrevista com Marcos, Barcelona, agosto de 2012). 
Embora não esteja mais feliz no relacionamento, afirma que vai levando. Sua experiência não é diferente da experiência de outros imigrantes na Espanha ou mesmo na Europa, que têm passagens pela prisão ou pelos Centros de Internamento de Estrangeiros, devido ao envolvimento com atividades ilícitas na Espanha ou mesmo porque são enquadrados como imigrantes ilegais. Os CIE, centros em que imigrantes nessas condições são detidos, são considerados como uma espécie de prisão, com a desvantagem de que não se tem uma definição formal do status dos que ali estão, o que agudiza a situação de indefinição dos estrangeiros nesses lugares ${ }^{21}$.

\section{Considerações finais}

Os fragmentos das histórias aqui trazidas permitem entrever contradições em torno das narrativas que associam o contexto de mercado transnacional relacionado à homossexualidade na cidade de Barcelona com noções de liberdade, enquadradas a partir da possibilidade de expressão da sexualidade no âmbito desse mercado. Para Pablo, Jonas, Juninho e Marcos, essa liberdade, ainda que possa ser acionada como valor, encontra restrições na insegurança e no trabalho que realizam; no próprio preconceito verificado em cidades como Sória; na consequente fragilização provocada pelas políticas migratórias europeias somadas à noção de tráfico sexual, tão bem discutida por Adriana Piscitelli (2013); e no risco do encarceramento como política de expulsão e controle de imigrantes, com ou sem documentos. As possibilidades de agência - ou de torção dessas relações - aparecem quando esses rapazes usufruem do mesmo contexto de lazer e de consumo, quando optam pelo casamento com espanhóis - mescla de cálculo e sentimento, como em outros casamentos - de modo a obter a cidadania europeia ou quando se utilizam do próprio deslocamento entre diferentes países e da habilidade que isso lhes proporciona em prol de seus interesses materiais ou eróticos. Seus trânsitos são, assim, modulados pelo contexto do mercado, mas também pelo impacto das políticas de regulação migratória empreendidas pelos Estados nacionais.

Suas experiências contrastam com as narrativas mais oficiais associando a cidade de Barcelona à liberdade e à fruição experimentada no turismo. Em Barcelona, ouvi a seguinte expressão: "no paqui, no party", em referência aos paquistaneses que se arriscam cotidianamente nas praias e plazas da cidade, vendendo cerveja clandestinamente e provendo a fruição de locais e turistas. Da mesma maneira, o mercado de lazer voltado para gays sustenta-se também a partir do trabalho - sexual ou não - de imigrantes. No caso brasileiro, a enorme desigualdade social é transportada também para os contextos de turismo e imigração, ainda que aí apareça de forma deslocada.

Sustento que o próprio deslocamento desses sujeitos expõe desigualdades e ao mesmo tempo suas brechas - que são espécie de contrapartida da produção de Barcelona como um lugar imaginado, como uma cidade que "inspira a viver 
em liberdade". Essas brechas atualizam-se em cada permanência; em cada percurso que um imigrante sem documentos - ou até com documentos - faz na cidade, virando-se ${ }^{22}$ pelas suas territorialidades; em cada burla de sistemas restritivos de direitos, de mobilidades e inclusive de acesso ao consumo de bens e serviços. Nesses percursos, meus interlocutores encontravam-se com diferentes limitações, enredando-se nas dinâmicas de funcionamento do mercado e ao mesmo tempo nas políticas de enquadramento das suas mobilidades nos marcos regulatórios dos Estados nacionais. Contudo, em que pesem as diferenças entre as dinâmicas do mercado e as regulações do Estado, ambos os contextos se mostravam campo de manejo de constrangimentos sociais e legais. Tais campos de ação se constituem em meio aos trânsitos, ainda que controlados, operados por sujeitos que, quando atravessam fronteiras nacionais, são também produzidos como sexualizados e racializados.

\section{Notas}

1 - Trata-se de pesquisa de pós-doutorado financiada pela FAPESP (Fundação de Amparo à Pesquisa do Estado de São Paulo) e desenvolvida no Núcleo de Estudos de Gênero Pagu/ Unicamp entre 2011 e 2014. Durante a pesquisa me debrucei sobre trânsitos de homens gays brasileiros em diferentes escalas, local, regional e internacional, tentando apreender algo sobre como nesses trânsitos se deslocavam diferenças e desigualdades, bem como se produziam sentidos de lugar, desejos eróticos e também desejos de consumo. A pesquisa se desenvolveu nas cidades de São Paulo, Recife e Barcelona, sendo que este artigo refere aos resultados relacionados a essa última cidade.

2 - Os dados referem-se a brasileiros relacionados como estrangeiros; assim, excluem-se os imigrantes brasileiros com nacionalidade espanhola. Os números decorrem dos relatórios de empadronamento, ou seja, do registro de imigrantes nas prefeituras do país, independente da situação de regularização dos documentos. Ainda assim, são consideráveis os dados que apontam, entre 2008 e 2012, a inversão do saldo migratório espanhol em relação a estrangeiros: de país que recebe imigrantes, a Espanha passa a ser um país emissor de imigrantes, que retornam a seus países de origem ou buscam outras opções. Em relação aos brasileiros, os dados de chegada a Espanha em 2012 apontam um decréscimo de 15,4\%, ainda que o Brasil figure naquele momento entre os 10 principais países de origem de estrangeiros. Tais dados, ainda que não revelem um panorama completo e cristalino da presença de brasileiros na Espanha quando realizei a pesquisa, são expressivos no sentido de delinear tendências mais amplas, que compõem o contexto de que trato neste artigo. (Fonte: Instituto Nacional de Estadística (INE-ES). Cifras de Población a 1 de enero de 2013 - Estadística de Migraciones 2012. Nota de Prensa. Julho de 2013. Disponível em: http://www.ine.es/prensa/np788.pdf acesso em 04 abr 2016.)

3 - Trata-se de relatório de pesquisa realizado através de parceria entre o Conselho Nacional de Imigração (CNIg), o Ministério do Trabalho e Emprego do Brasil e o International Centre for Migration Policy Development (ICMPD) no marco do projeto "Itineris: Proteção dos direitos dos migrantes contra a exploração, do Brasil para Estados-Membros da União Europeia". Ver: ICMPD, 2013.

4 - Atualizo a já explorada ideia foucaultiana de que a sexualidade, como dispositivo, é produzida a partir de redes de saber-poder que incluem a gestão da vida e os saberes 
biomédicos bem como aparatos jurídicos (FOUCAULT, 1977). Nos últimos anos temos produzido na antropologia brasileira um volume de trabalhos, no qual minhas próprias pesquisas se inserem (FRANÇA, 2006; 2012), que tem nos permitido avançar na perspectiva analítica que considera o mercado e processos relacionados ao consumo diante de contextos de produção de subjetividades, identidades e categorias sociais.

5 - LGBT refere a Lésbicas, Gays, Bissexuais, Travestis e Transexuais.

6 - Chapero é o termo correntemente utilizado em referência a homens que fazem sexo mediante pagamento em dinheiro. A atividade se organiza principalmente a partir de pisos (apartamentos), saunas e sites de acompanhantes. Além disso, lugares de circulação relacionados ao mercado de lazer gay, como as discotecas, também eventualmente são frequentados por chaperos em busca de clientes.

7 - A pesquisa realizada em 2006 pela Fundación Triángulo, sediada em Madrid, com 101 chaperos atuantes na cidade, trouxe o dado de que $55 \%$ deles é de origem brasileira. Em reunião com ativistas da ONG Stop Sida, atuante em Barcelona como uma das principais associações de combate e prevenção ao HIV/Aids e responsável por projetos de prevenção voltados para trabalhadores do sexo, a presença de trabalhadores brasileiros no mercado do sexo na cidade também foi enfatizada (Fundación Triángulo, Disponível em: http://www. fundaciontriangulo.org/documentacion/documentos/trabajadoresmasculinos.pdf Acesso em 08 nov 2012.

8 - CASTÁN, Patrícia. Gaycelona en remojo. El periódico. Disponível em: http://www. elperiodico.com/es/noticias/barcelona/gaycelona-remojo-2180792.

Acesso 24 out 2015.

9 - Fonte: Matinée Group (2013a) “Circuit Festival - Biggest International Gay \& lesbian event: Dossier 2013". (Julho), Barcelona.

10 - La Vanguardia. Los extranjeros suponen el $80 \%$ de los participantes en el Circuit Barcelona. Fonte: http://www.lavanguardia.com/local/barcelona/20130816/54378604731/festival-gayextranjeros-suponen-80-participantes-circuit-barcelona.html acesso 24 out 2015.

11 - O bairro é conhecido também como Gayxample, dada a concentração de lojas, bares, restaurantes, boates e até mesmo hotéis voltados para o público gay.

12 - O hotel pertence a uma rede de hotéis com estabelecimentos também em Berlim e llhas Canárias, voltada preferencialmente para um público de gays e lésbicas. Por isso, a inversão do termo "gay friendly", comumente utilizado para sinalizar a receptividade a pessoas gays e lésbicas em locais voltados majoritariamente para um público "heterossexual".

13 - Pegação é categoria êmica em referência a trocas sexuais furtivas e muitas vezes anônimas entre homens.

14 - Termo êmico que designa o uso de psicoativos ilícitos.

15 - Porosidades entre diferentes "mercados" fazem-se notar nos trabalhos presentes no livro organizado por Piscitelli, Assis e Olivar (2012). Destaco o fato de que tais porosidades raramente são tomadas como objeto de análise no campo de trabalhos relacionados à homossexualidade, em que muito comumente se separa mercado de lazer do mercado do sexo tanto no âmbito do empírico-metodológico como no âmbito analítico - o que torna ainda mais relevante a troca de experiências de pesquisa no sentido de produzir uma análise que dê conta da diversidade de situações que encontramos em campo. De todo modo, é preciso ressaltar que, embora essa discussão não estivesse claramente formulada em pesquisas que lidaram com prostituição masculina e/ou lugares de sociabilidade e lazer relacionados à homossexualidade, estudos clássicos nesse campo, desde Reiss Jr. (1961), já permitiam conexões nesse sentido. $O$ exemplo mais acabado provavelmente encontra-se no trabalho de Néstor Perlongher (2008). 
16 - Talvez seja esse o tipo de cálculo realizado por imigrantes brasileiros na Espanha que expressavam receio diante de um retorno ao Brasil, postura mencionada na introdução deste artigo a partir de pesquisa realizada pelo ICMPD (2013).

17 - A expressão perdendo plumas faz referência ao ato de fechar, dar close, ou seja, adotar comportamento e gestual mais feminino e considerado menos discreto, atitude que possivelmente revelaria a identidade sexual.

18 - Tal aspecto é muito bem explorado na pesquisa de Natália Corazza Padovani (2015), sobre mulheres brasileiras e espanholas entre prisões no Brasil e na Catalunha.

19 - Essas fronteiras, em São Paulo, têm sido muito bem exploradas por pesquisadores como Vera Telles e outros que se atêm às redes do trabalho na cidade (TELLES, 2011).

20 - Gogo boy - Trata-se de homem musculoso estereotipado, que faz shows sensuais, eróticos em troca de dinheiro. Gogo boys trabalham, geralmente, em Clubes e Casas Noturnas, mas também se apresentam em festas de despedida de solteiro para mulheres. Eles não atendem apenas a grupos LGBTI e o seu trabalho gera polêmica social, pois é comumente associado à prostituição de homossexuais e heterossexuais, já que estes últimos também podem trabalhar como gogo boys e obter dinheiro para as despesas de suas condições materiais de vida cotidiana (Nota do Editor).

21 - Atualmente, o CIE de Barcelona encontra-se fechado para reformas e há uma grande mobilização social que reivindica seu fechamento permanente.

22 - Utilizo o termo em alusão à categoria de viração, tal como utilizada por Gregori (2000), no seu estudo sobre meninos que viviam nas ruas da cidade de São Paulo, para descrever a prática de lidar com diferentes interlocutores e articular diferentes estratégias de sobrevivência e satisfação de necessidades básicas.

\section{Referências}

BRAH, A. Diferença, diversidade, diferenciação. Cadernos Pagu. Campinas-SP, v. 26, p. 329376, jan./jun. 2006.

CASTÁN, P. Gaycelona en remojo. El periódico. Disponível em: http://www.elperiodico.com/es/noticias/barcelona/gaycelona-remojo-2180792. Acesso 24 out 2015.

FERNANDES, D; NUNAN, C. O Imigrante brasileiro na Espanha: perfil e situação de vida em Madri. In: Anais do XVI Encontro Nacional de Estudos Populacionais, Caxambu, 2008. Disponível em: http://www.abep.nepo.unicamp.br/encontro2008/docsPDF/ABEP2008_1160.pdf

FOUCAULT, M. História da Sexualidade: A vontade de saber. . Vol. 1. São Paulo: Graal, 1977.

FRANÇA, I. L. Cercas e pontes: o movimento GLBT e o mercado GLS na cidade de São Paulo. Dissertação (Antropologia Social)-São Paulo: PPGAS-FFLCH/USP, 2006.

Consumindo lugares, consumindo nos lugares: homossexualidade, consumo e subjetividades na cidade de São Paulo. 1. ed. Rio de Janeiro: EDUERJ/CLAM, 2012.

FUNDACIÓN TRIÁNGULO. Trabajadores masculinos del sexo: aproximación a la prostitución masculina en Madrid, 2006.

Disponível em: 
http://www.fundaciontriangulo.org/documentacion/documentos/trabajadoresmasculinos.pdf Acesso em 08 nov 2012

GREGORI, M. F. Viração: experiências de meninos nas ruas. 1. ed. São Paulo: Companhia das Letras, 2000.

ICMPD - INTERNATIONAL CENTRE FOR MIGRATION POLICY DEVELOPMENT. Migração BrasilEuropa. A situação dos migrantes brasileiros na Espanha e Portugal e de portugueses e espanhóis no Brasil: aspectos legais e vivências. Relatório de pesquisa. International Centre for Migration Policy Development- ICMPD: Vienn, 2013.

Disponível em: http://goo.gl/icsKhc

Acesso em 04 abr 2016.

INSTITUTO NACIONAL DE ESTADÍSTICA - INE-ES. Cifras de Población a 1 de enero de 2013 Estadística de Migraciones 2012. Nota de Prensa. Julho de 2013.

Disponível em: http://www.ine.es/prensa/np788.pdf

Acesso em 04 abr 2016

LA VANGUARDIA. Los extranjeros suponen el $80 \%$ de los participantes en el Circuit. In: La Vanguardia. Barcelona. Disponível em : http://www.lavanguardia.com/local/ barcelona/20130816/54378604731/festival-gay-extranjeros-suponen-80-participantescircuit-barcelona.html Acesso em 24 out 2015.

MARTINÉE GROUP. Circuit Festival - Biggest International Gay \& lesbian event. Dossier. Barcelona, 2013.

MASSEY, D. Pelo espaço: uma nova política da espacialidade. Rio de Janeiro: Bertrand Brasil, 2012.

MCCLINTOCK, A. Couro Imperial: raça, gênero e sexualidade no embate colonial. 1. ed. Campinas: Editora da Unicamp, 2010.

PADOVANI, N. C. Sobre casos e casamentos: afetos e "amores" através de penitenciárias femininas em São Paulo e Barcelona. Tese (doutorado em Antropologia Social). Programa de Pós-Graduação em Antropologia Social. IFCH - Instituto de Filosofia e Ciências Humanas, Universidade Estadual de Campinas. Campinas, 2015.

PERLONGHER, N. O negócio do michê: prostituição viril em São Paulo. São Paulo: Perseu Abramo, 2008.

PISCITELLI, A. Trânsitos: brasileiras nos mercados transnacionais do sexo. 1. ed. Rio de Janeiro: EDUERJ/CLAM, 2013.

PISCITELLI, A; ASSIS, G. O.; OLIVAR, J. M. N. (org.) Gênero, sexo, amor e dinheiro: mobilidades transnacionais envolvendo o Brasil. 1a ed. Campinas: Pagu/Núcleo de Estudos de Gênero/ Unicamp, 2011.

REISS JR., A. J. The social integration of queers and peers. Social Problems. New York. Vol. 9, pp: 102-120, 1961.

SCHILLER, N. G; SALAZAR, N. B. Regimes of mobility across the globe. Journal of Ethnic and Migration Studies, Sussex, vol. 39, 2012, pp.183-200.

TELLES, V. S. A cidade nas fronteiras do legal e ilegal. 1. ed. Belo Horizonte: Argvmentvm, 2011. 


\title{
RESUMO
}

O artigo, elaborado a partir de pesquisa realizada em Barcelona entre 2012 e 2013, aborda as diferenças e desigualdades que cercam o cotidiano de imigrantes gays brasileiros na cidade, tendo como cenário o contexto do mercado voltado para gays e lésbicas. Tais experiências são contrastadas com um discurso muito presente do mercado de turismo, que atribui à cidade de Barcelona sentidos relacionados à liberdade e fruição. Sustento que os próprios deslocamentos realizados pelos imigrantes em meio a esse cenário afirmam, desafiam e deslocam normas e regulações. Ao mesmo tempo, reposicionam diferenças e desigualdades sociais que marcam o contexto brasileiro e se apresentam de forma renovada em espaços transnacionais. Ao atravessar fronteiras nacionais, os imigrantes são também produzidos como sexualizados e racializados, o que surge como fonte de constrangimento social, mas também configura campos de ação a partir do manejo da diferença.

Palavras-chave: homossexualidade, migração, gênero

\begin{abstract}
The article presents results of a research done in Barcelona between 2012 and 2013. The context of the gay market in that city was the setting for the analyzes that approach differences and inequalities related to gay brazilian migrants in their daily life. Their experiences produce a contrast to discourses of touristic agents that describe Barcelona as a city of freedom and joy. Their displacements dare rules and regulations while repositioning diferences and inequalities which mark brazilian social context. When trespass national borders, migrants are produced as sexualized and racialized, which sets both social boundaries and agency fields open by the management of difference.
\end{abstract}

Keywords: homosexuality, Migration, gender 